


\section{SISTEMAS INTERNACIONAIS DE APRENDIZAGEMI PROFISSIONAL: UMA ANÁLISE COMPARATIVA EM ALGUNS PAÍSES DESENVOLVIDOS E EMERGENTES}

\section{INTERNATIONAL SYSTEMS OF VOCATIONAL LEARNING: A COMPARATIVE ANALYSIS IN SOME DEVELOPED AND EMERGING COUNTRIES}

José Rodrigo Paprotzki Veloso* Marta M. Assumpção Rodrigues**

*Mestre em Gestão de Políticas Públicas pela Escola de Artes, Ciências e Humanidades da Universidade de São Paulo (USP).

E-mail: rodrivel@usp.br

**Ph.D. em Ciência Política pela Universidade de Notre Dame. Professora no curso de Gestão de Políticas Públicas da Escola de Artes, Ciências e Humanidades da USP e pesquisadora associada no Núcleo de Pesquisa de Políticas Públicas da mesma Universidade.

E-mail:mmar@usp.br

Recebido para publicação em: 25.10.2015

Aprovado em: 7.12.2015

\section{Resumo}

Este trabalho examina as políticas públicas que articulam educação e trabalho para a juventude, de uma perspectiva comparada, contrapondo as trajetórias de países desenvolvidos e em desenvolvimento. Mais especificamente, focaliza a política de formação de aprendizes (Aprendizagem) nos casos de Alemanha, Inglaterra, França, Estados Unidos, Brasil, África do Sul e Índia. O objetivo é revelar que há algo que antecede os formatos atuais que, ao formar imagens políticas específicas, ilumina os cenários dos sistemas de Aprendizagem dos países analisados. Lança mão do enfoque da trajetória histórica (path dependence) para analisar as particularidades de cada caso.

Palavras-chave: Sistemas de Aprendizagem. Educação para o Trabalho. Política Comparada. Mercado de Trabalho.

\section{Abstract}

This research examines the public policies that articulate education and work for youth in a comparative perspective, opposing the paths of developed and developing countries. More specifically, it focuses on apprentices' education policy (Learning) in the case of Germany, England, France, United States, Brazil, South Africa and India. The purpose is to reveal that there is something that precedes the current formats that, when forming specific political images, illuminates the Learning systems scenarios of the analyzed 
countries. It makes use of the historical path (path dependence) to analyze the peculiarities of each case.

Keywords: Learning Systems. Education for Work. Compared Policy. Labor Market.

\section{Resumen}

Esta investigación examina las políticas públicas que articulan educación y trabajo para la juventud desde una perspectiva comparada, contraponiendo las trayectorias de países desarrollados y en desarrollo. Más específicamente, se centra en la política de formación de aprendices (Aprendizaje) en los casos de Alemania, Inglaterra, Francia, Estados Unidos, Brasil, Sudáfrica e India. El objetivo es revelar que hay algo que precede los formatos actuales que, al formar imágenes políticas específicas, ilumina los escenarios de los sistemas de Aprendizaje de los países analizados. Lanza mano del enfoque de la trayectoria histórica (path dependence) para analizar las particularidades de cada caso.

Palabras clave: Sistemas de Aprendizaje. Educación para el Trabajo. Política Comparada. Mercado Laboral.

\section{Introdução}

Este trabalho visa problematizar os rumos das políticas que articulam educação e trabalho para a juventude, contrapondo as trajetórias de países desenvolvidos e em desenvolvimento. O escopo da análise será dirigido especificamente à política pública que se presta à formação de aprendizes. A despeito da possibilidade de conceituá-la de diversos modos, convém definir a política de Aprendizagem ${ }^{1}$ de forma preliminar, a partir de uma visão ampliada - i.e., para além da visão restrita ao processo educacional e do aspecto legalista -, de modo a ressaltar sua relevância multidisciplinar. Nesse sentido, empresta-se a definição de Aprendizagem de Fuller e Unwin (1998, p. 154), para quem

Apprenticeship is an international concept which provides a structure within which young people can learn and, most importantly, demonstrate their abilities and potential whilst, at the same time, discovering their identity. In traditional societies, apprenticeship was associated with rites of passage [...]: it includes the cultural and social aspects of going to, and being at, work which help socialize apprentices into workplace (and

adult) roles.

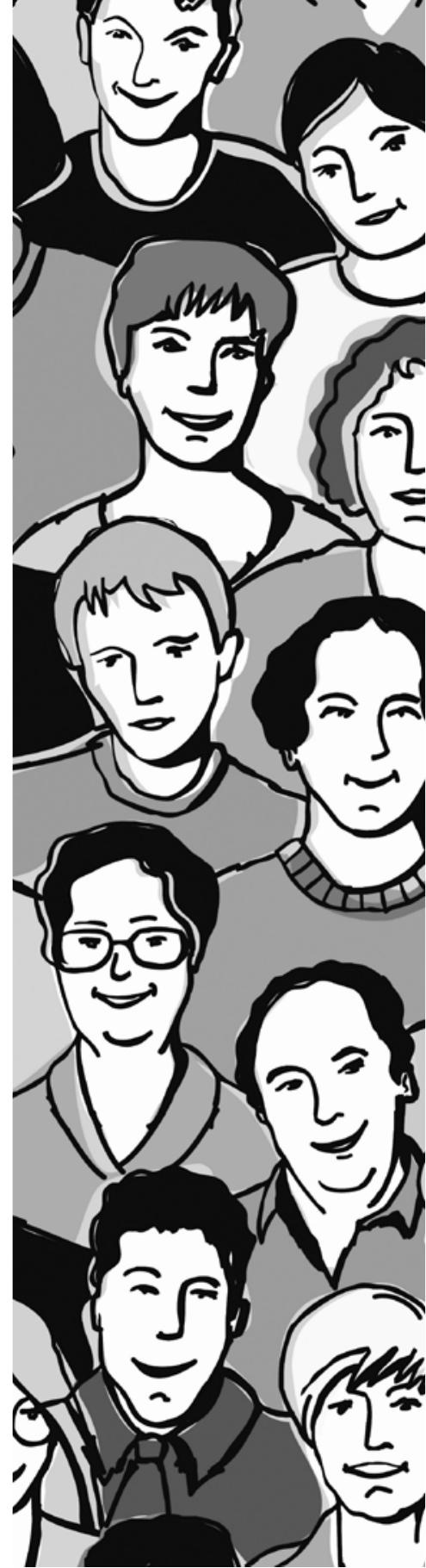




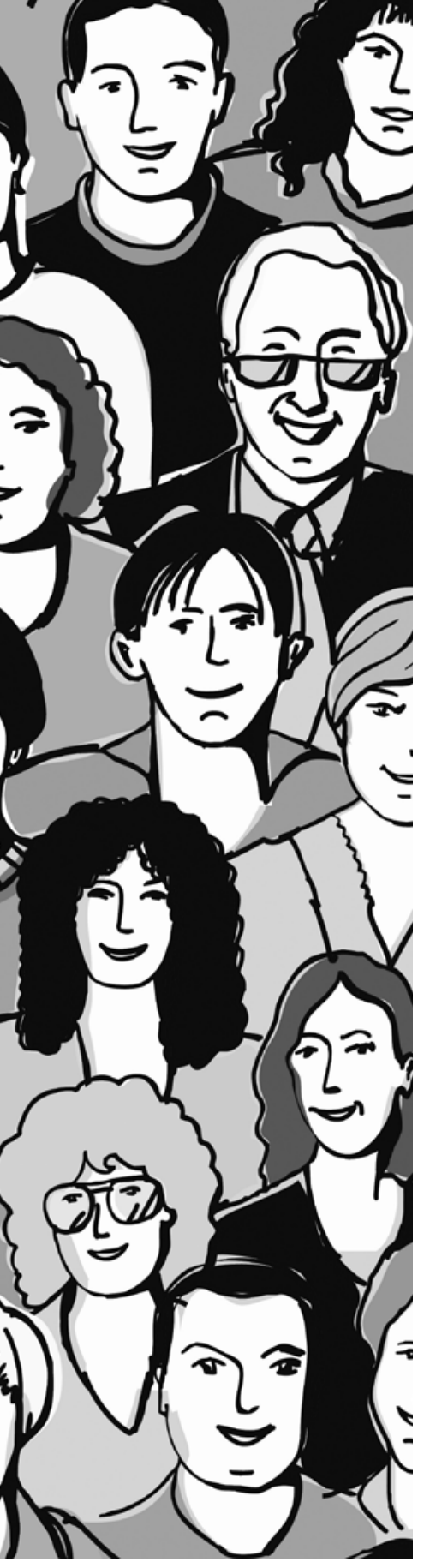

O objetivo deste texto é revelar que há algo que antecede os formatos atuais e que pode explicar os cenários da Aprendizagem dos países analisados, formando imagens políticas específicas, que se constituem ao longo do tempo. Assim, em um primeiro momento, serão analisados os modelos de Aprendizagem europeus, cuja tradição da educação profissional gremista (caracterizada por conjunturas críticas diversas) resultou em políticas públicas distintas, marcadas por ampla governança. Tais modelos apresentam características aproximadas com os valores da administração pública de seus respectivos países. Ainda que diferentes entre si, são comumente divulgados por agências internacionais como benchmarking à implantação ou correção de rota das políticas de Aprendizagem de outros países, sobretudo àqueles em desenvolvimento. Na sequência, serão analisados os modelos de três países pertencentes ao grupo Brasil, China, Rússia e Índia (Brics). Eles revelam não apenas a necessidade de inserção na agenda da economia global, mas também os desafios específicos dos países em desenvolvimento, cujas culturas e histórias são elementos preponderantes que explicam o fato de a Aprendizagem não se dar da mesma forma como nos países desenvolvidos. Por fim, será apresentado o modelo norte-americano, que agrega, de certa maneira, o antigo e o novo, no sentido que traz consigo características próprias de um país desenvolvido, sem a tradição gremista, mas com a necessidade de enfrentamento de algumas questões que também são comuns àqueles em desenvolvimento.

\section{Aprendizagem e suas histórias}

A Aprendizagem é uma ação pública ordenada que os Estados desenvolvidos ou em desenvolvimento têm sistematizado, visando não apenas facilitar a transição dos jovens do mundo da educação para o mundo do trabalho, mas, principalmente, qualificar a força de trabalho juvenil, que está mais exposta ao desemprego que tem se alastrado rapidamente, em diversos países, como consequência das crises econômicas mundiais mais recentes. Sabe-se, porém, que a eficácia da política de Aprendizagem tem oscilado muito de país para país. Compreender as causas dessa variância implica o exame das trajetórias de desenvolvimento dos diversos países de uma perspectiva histórica e comparada. A trajetória histórica (path dependence) de cada país traz à tona contradições e desafios específicos. Partindo dessa perspectiva, recebe-se de Pierson e Skocpol (2008) a ideia de que a eficácia das políticas depende não apenas dos fatos ocorridos em determinado momento do passado e que afetam os eventos presentes, mas, principalmente, da probabilidade de avançar uma etapa, seguindo o mesmo percurso. Em outras palavras, a eficácia da política (ou seu processo de realimentação positiva) aumenta cada vez que tal caminho é seguido. 
Dessa forma, a análise que se segue investiga os rumos e as metamorfoses das políticas públicas nacionais de Aprendizagem, para promover uma discussão que vá além da natureza pedagógica ou da esfera do direito. Negligenciar a trajetória histórica significa considerar as realidades como dadas e limitadas a fatores tópicos - como estratégias de ensino, promulgação de leis ou, pior, a mera incapacidade de alguns Estados de dar conta de seus desafios. No âmbito da Aprendizagem especificamente, o argumento é quais cenários históricos são atribuídos às características da política em cada país. A evolução das políticas de educação profissional para os jovens tem sido estudada por cientistas sociais, historiadores e educadores há tempos.

Sobre a composição de forças e governança nos modelos da educação profissional da Aprendizagem, nos anos 1980, autores europeus, a partir de Wolfgang Streeck, passam a se referir ao processo de transformação das instituições de formação institucional em diversos países - como Alemanha e França (SCHRIEWER, 1990), Inglaterra, Estados Unidos e Japão, além de, mais recentemente, Holanda, Dinamarca e Suécia (THELEN, 2003, 2004).

Estudos mais recentes (ASSUMPÇÃO RODRIGUES, 2013, 2014; VELOSO, 2015) têm avaliado que a Aprendizagem no Brasil e na África do Sul, por exemplo, difere dos modelos europeus, menos pelo fato de a Europa ter iniciado sua industrialização mais de um século antes destes, do que pela influência negativa que a escravidão e segregação racial impregnaram nas questões relacionadas ao acesso ao mercado de trabalho formal nestes países. Assim, se as iniciativas dos Estados relativas às políticas de educação para o trabalho compuseram, no Brasil, uma imagem política de opção de segunda categoria, na África do Sul, ela ficou estigmatizada como política a serviço do apartheid.

\section{- Alemanha}

No caso da Alemanha, por exemplo, a política de Aprendizagem se sustenta por uma malha de responsabilidades compartilhadas. Dentro do poder público, o governo federal assume visão estratégica a partir do Ministério de Economia e Tecnologia, embora haja processos descentralizados de maior articulação e operacionalização no âmbito das províncias e comunidades.

O sistema público de Aprendizagem alemão é especial pela sua tradição conferiu, entre 1870 e 1897, papel fundamental às câmaras de comércio e manufatura - e pela valorização sistemática da formação tradicional - como política pública. O ponto central de sustentabilidade deve-se ao papel que o Estado exerceu na mediação dos interesses entre os grêmios, as indústrias e os sindicatos alemães. O papel dessas câmaras como mediadoras entre a liberdade econômica individual e a cooperação institucional resultou em

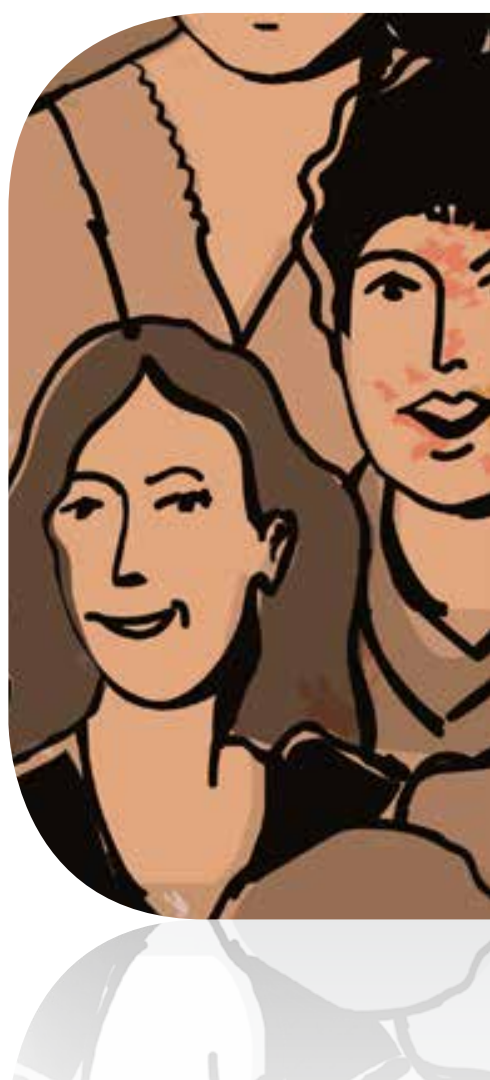

Negligenciar

a trajetória histórica significa considerar as realidades como dadas e limitadas a fatores tópicos

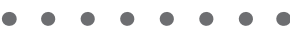


obrigações coletivas que foram respeitadas sempre que o sistema político foi democrático, assim promoveu aprimoramentos graduais e constantes do arranjo funcional da Aprendizagem ao longo das décadas (SCHRIEWER, 1990).

Além disso, a trajetória da Aprendizagem alemã caracterizou-se por conjunturas críticas marcantes, como as disposições legais em relação ao papel conferido pelo Estado às câmaras locais no fim do século 19, a ascensão do nazismo e o marco legal do modelo atual de 1969. Ressalta-se, ainda, que os sindicatos de trabalhadores nunca se opuseram à formação de aprendizes nas fábricas, de forma que o produto dessa iniciativa sempre foi a valorização da educação profissional como patrimônio nacional alemão. O arranjo de sustentação entre Estado, câmaras, sindicatos e empresas foi emblemático para superação de problemas conjunturais enfrentados desde a crise na República de Weimar até a reunificação nos anos 1990.

O modelo de Aprendizagem alemão é mundialmente conhecido como sistema dual porque a formação profissional é realizada em dois locais (empresas e escolas profissionalizantes - berufsschule)2 ${ }^{2}$. Tem como objetivo fornecer, de forma planejada, educação profissional de base ampla para a prática de uma atividade profissional como trabalhador qualificado em mais de 300 famílias ocupacionais reconhecidas, de modo a garantir um padrão nacional uniforme que corresponda às exigências de cada ocupação e às qualificações parametrizadas da União Europeia. Em 2011, foram registrados 1,5 milhão de aprendizes (SMITH; KEMMIS, 2013).

\section{- França}

Assim como o modelo alemão, a política pública na França se sustenta por uma malha de responsabilidades compartilhadas. Dentro do poder público, o governo federal assume visão estratégica a partir do Ministério da Educação Nacional, cuja responsabilidade recai especificamente no Departamento de Inspeção da Aprendizagem, o Service Académique d'Inspection de l'Apprentissage (SAIA). Assume também as diretrizes pedagógicas dos centros públicos que formam os aprendizes (elemento central na política pública francesa), embora a gestão operacional se dê em nível regional. Há duas comissões nacionais para constante atualização dos perfis ocupacionais, parametrização com as qualificações europeias e assessoria à operacionalização em âmbito regional. Todavia, como as políticas de qualificação profissional desempenham papel significativo na malha de relações do Estado de bem-estar social francês, há ampla articulação das comissões consultivas com os parceiros sociais no desenvolvimento da política 
pública, além do papel de destaque que as câmaras de comércio e indústria assumiram na segunda metade do século 20 para validação dos contratos. Esse arranjo participativo, porém, nem sempre foi assim.

Historicamente, a legislação sobre a educação profissional (1791), que resultou da Revolução Francesa, considerava ilegal toda e qualquer forma de corporação não estatal, bem como a manutenção de privilégios corporativistas, o que liquidou os grêmios e introduziu a liberdade industrial ilimitada. O radicalismo foi tamanho que as associações profissionais de qualquer tipo eram consideradas como atentado contra os princípios revolucionários. Essa disposição impediu o desenvolvimento de associações, federações e sindicatos até o fim do século 19 e implicou em um problema de legitimidade no trato com os aprendizes (SCHRIEWER, 1990). Após diversas rupturas estruturais do modelo de formação francês dirigido aos jovens, em 1878, o Estado passa a ampliar sua responsabilidade com a criação das écoles d'apprentissage. A partir do pós-guerra, como reflexo da defasagem francesa em relação ao industrialismo alemão, nascem os Centros de Formação de Aprendizes (CFA), em 1961. Ao traçar um paralelo com o modelo alemão, que centraliza seu modelo na prática profissional na empresa, o modelo francês apresenta centralidade nos CFA. A partir de 1971, para elevar a qualidade dos programas, a Aprendizagem insere as iniciativas de qualificação profissional dentro do sistema educacional francês, em 1971. Entre 1987 e 1992, os programas dos CFA foram reestruturados para acesso à maior complexidade, implicando, desde então, no aumento progressivo de jovens interessados na Aprendizagem.

Se comparada aos modelos inglês e alemão, a segunda maior economia europeia, com 425 mil aprendizes, em 2011 (SMITH; KEMMIS, 2013), a França desenvolve uma política pública com ênfase acentuada na formação teórica, valorizada pela etapa no CFA como alicerce significativo do sistema educacional ${ }^{3}$, que é objeto de valorização por atores internacionais quando buscam modelos de exportação da Aprendizagem. Porém, os altos índices de desemprego juvenil (26\%, em 2013) têm prejudicado a imagem da política que o Estado (e isso não é um caso isolado da França) tem buscado valorizar junto à população jovem.

\section{- Inglaterra}

Apesar de a Aprendizagem inglesa compartilhar a longevidade com a alemã, elas têm pouco em comum. Suas trajetórias são distintas e os atores envolvidos nessa política tiveram objetivos e valores distintos. Isso também ocorreu com relação ao caso da França. Ao contrário de Alemanha e França, a Aprendizagem, na Inglaterra, sempre foi um assunto da agenda sindical e o trabalho aprendiz foi considerado, nesse contexto, um elemento-chave da precarização do trabalho juvenil (THELEN, 2004).

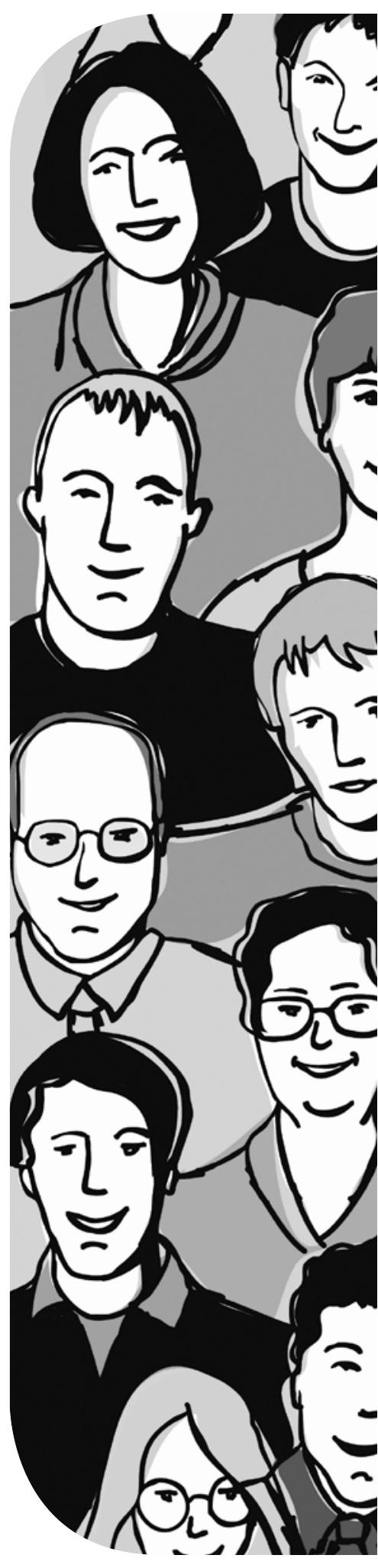


Para enfrentar esse problema e remediar o impacto de um treinamento profissional pobre sobre o desempenho opaco da economia do pós-guerra (PEMBERTON, 2001), em 1964, a Lei de Treinamento Industrial nasce atribuindo poderes ao Ministério do Trabalho britânico para compor os

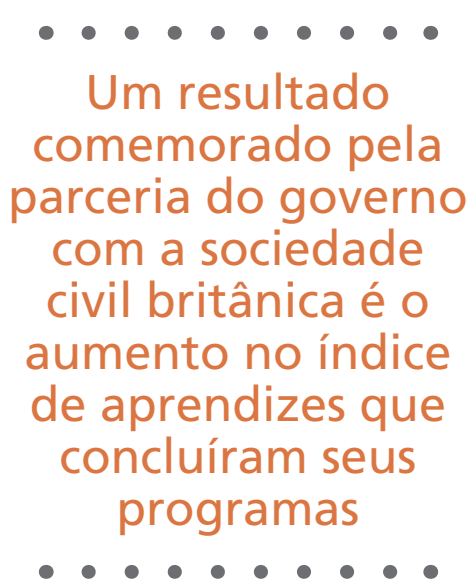

Conselhos de Treinamento Industrial (Industrial Training Boards - ITB) para empregadores e trabalhadores participarem no desenho da política. A partir de um sistema de imposto compulsório (semelhante ao do chamado Sistema S, no Brasil), os ITB passaram a se responsabilizar não só pela supervisão do treinamento nas indústrias, mas também pela oferta de uma ajuda de custo aos trabalhadores em treinamento. A partir dos anos 1980, enquanto esse sistema passou a ser considerado uma reforma fracassada, com impacto de baixa efetividade, que ainda dialogava com o fordismo (KING, 1993; PAGE, 1967; PRAIS, 1995), o modelo de Aprendizagem britânico foi reestruturado para um formato mais dinâmico ${ }^{4}$ e focado no atendimento às lacunas de qualificação do mercado de trabalho. Dessa vez, inspirado no New Public Management (1995).

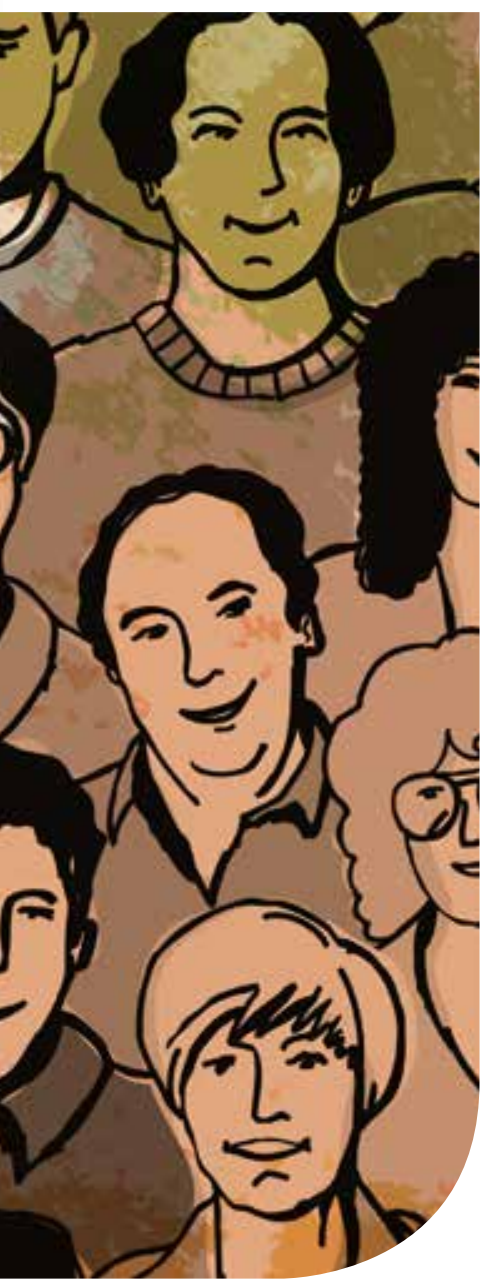

Mais recentemente, com o objetivo de incrementar a qualidade do sistema, o governo britânico tem viabilizado a organização de fóruns, comitês e pesquisas de avaliação, bem como estreitado sua relação com os governos locais. Ao mesmo tempo, apesar da tradição inglesa de pouca intervenção na relação empregatícia, tem-se promovido também, desde 2011, maior presença do Estado na regulamentação das disposições trabalhistas e educacionais da Aprendizagem. Na atualidade, essa política é responsabilidade do Sistema de Aprendizagem Nacional (National Apprenticeship System - NAS), subordinado ao Departamento de Negócios, Inovação e Habilidades, e é vista como positiva por 90\% dos empregadores (STEEDMAN, 2010); os ITB, por sua vez, atuam apenas no setor de construção.

Um resultado comemorado pela parceria do governo com a sociedade civil britânica é o aumento no índice de aprendizes que concluíram seus programas, que foi de $36,7 \%$, em 2004/2005, e atingiu o dobro $(73,8 \%$ ), em 2011/2012 (RAIKES, 2015) - 457 mil aprendizes em 2011 (SMITH; KEMMIS, 2013). No entanto, um olhar mais detido desses dados vê que esse aumento está altamente concentrado em grupos de trabalhadores com mais de 25 anos, motivados pela busca de requalificação de pessoas que já atuam no mercado de trabalho. Nesses termos, ainda que se argumente tratar-se de um mecanismo preventivo ao desemprego adulto, perde-se o foco em proporcionar oportunidades de aprendizado ao público jovem, sobretudo, para dinamizar maior articulação da Aprendizagem ao sistema educacional inglês (DOLPHIN; LANNING, 2011). 


\section{- Estados Unidos}

Apenas recentemente, a Aprendizagem nos Estados Unidos se sustenta na condição de efetiva política pública, a partir de responsabilidades compartilhadas. O governo federal norte-americano assume a execução estratégica a partir do Departamento do Trabalho, assessorado por um comitê multirrepresentativo formado por trabalhadores, empresários, educadores e poder público, o Advisory Committee on Apprenticeship (ACA). Embora se trate de um programa federal, há processos descentralizados de maior operacionalização no âmbito estadual para controle burocrático e pelas sucursais locais do ACA para prover assessoria às empresas.

Durante décadas, a Aprendizagem foi considerada, no país, como iniciativa demasiadamente "europeia" (MARKHAM, 1967) e substituída por alternativas de formação de mão de obra germinadas no seio do empresariado local. Até o fim do século 19, não era observada como instrumento de qualificação de mão de obra pelos sindicatos, mas de controle de disponibilidade da oferta (compartilhando a mesma visão dos correspondentes ingleses). O governo só investia em algum tipo de atividade laboral no âmbito da educação formal nas escolas secundárias, e não na educação profissional per se. Finalmente, o patronato não tinha motivo para se queixar de ausência de mão de obra, pois os empresários inovaram, justamente, em termos da não dependência de mão de obra aprendiz, valendo-se, de forma articulada, do grande contingente de mão de obra qualificada disponível, da produção em massa e do desenvolvimento de técnicas relacionadas à administração da produção ${ }^{5}$.

Porém, vale observar que, nos Estados Unidos, a aprendizagem informal sempre foi amparada legalmente. Iniciativas como o School-to-Work Opportunities Act, de 1994, geraram mais jovens em situação de aprendizado nas empresas sem registro formal, o que incrementou os casos de precarização do mercado de trabalho juvenil. A conjuntura crítica que implicou em uma mudança dos rumos da política de Aprendizagem nos Estados Unidos surgiu apenas com a crise de 2008, quando o governo de George W. Bush decidiu revigorar e promover a Aprendizagem, tendo como influência as experiências recentes de modernização em países como Canadá, Inglaterra e Austrália que, aliás, compartilham valores semelhantes da gestão pública. Citada como $21^{\text {th }}$ Century Registered Apprenticeship, trata-se de uma política de Estado fortalecida durante a administração de Barak Obama, que visa promover articulação entre jovens maiores de idade e empresas.

Trata-se também de uma estrutura descomplicada, que busca a formalização da contratação dos jovens que tenham acessado a educação profissional em cursos pós-secundários. Assim, o país emprega a Aprendizagem não só como ferramenta para incrementar a empregabilidade juvenil, mas também para apresentar alternativas à trajetória tradicional do jovem norte-americano que vê a high school (ensino médio) como preparatória para ser acolhido

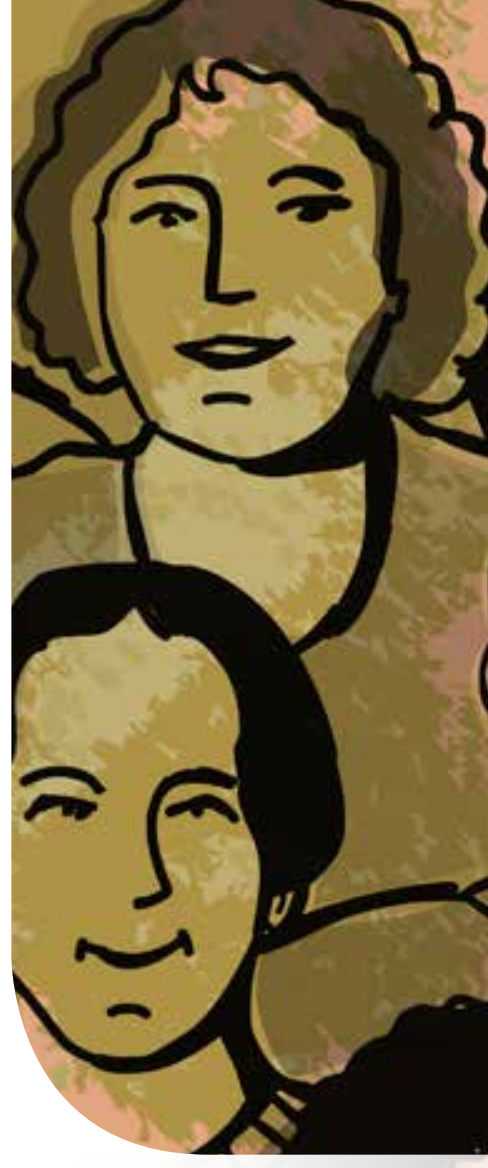


por uma universidade. No entanto, assim como na Inglaterra, parte significativa dos aprendizes adultos norte-americanos estão com mais de 25 anos.

Portanto, no caso dos Estados Unidos, há questões na agenda que se relacionam tanto às problemáticas dos países desenvolvidos (alternativas à trajetória profissional superior) como dos emergentes (casos de precarização de trabalho dos jovens decorrentes do modo informal). O que marca sua história, no entanto, é a ausência de mediação: se comparado ao modelo inglês, o Estado assume um papel menor, praticamente como fomentador de relações de emprego. No entanto, estimula fortemente a política pública por meio de incentivos: previsão de investimentos privados na ordem de US\$ 2 bilhões pelas empresas (para salário e infraestrutura), retorno de US\$ 50 em impostos para cada dólar investido, bem como índice de retorno sobre o investimento pelo empregador variando entre 300 e $1.000 \%$ (ADVISORY COMMITTEE ON APPRENTICESHIP, 2008).

\section{- Brasil}

O governo federal assume visão estratégica a partir do Ministério do Trabalho e Emprego (MTE), cuja responsabilidade recai na Secretaria de Políticas Públicas de Emprego (SPPE). O protagonismo da gestão da Aprendizagem brasileira é compartilhado também com a Secretaria de Inspeção do Trabalho (SIT), vinculada ao mesmo ministério, abrigando os auditores-fiscais do trabalho, agentes públicos com alto grau de discricionariedade para fazer cumprir a política pública, porém, baixo conhecimento sobre educação profissional.

A principal diferença da Aprendizagem brasileira, quando comparada às demais iniciativas de outros países, é seu caráter de obrigatoriedade. No Brasil, estabelecimentos públicos e privados são obrigados a contratar jovens entre 14 e 24 anos na condição de aprendizes ${ }^{6}$. Na prática, os jovens que a política de Aprendizagem busca atingir são provenientes de famílias de baixa renda, que dificilmente possuem oportunidades para obter uma educação de qualidade (MATSUZAKI, 2011). Para o desenvolvimento dos cursos de educação profissional aos jovens ${ }^{7}$, são habilitadas organizações paraestatais criadas por lei a partir dos anos 1940, denominadas Serviços Nacionais de Aprendizagem $(\mathrm{SNA})^{8}$, bem como entidades sociais e escolas técnicas públicas.

Verifica-se que a trajetória da Aprendizagem, no Brasil, passou por três conjunturas críticas importantes. Coincidente com a Aprendizagem não sistematizada no país até o fim dos anos 1930, o período inicial é marcado com abundância de mão de obra e restrição à assimilação imediata da população negra à força de trabalho. A Aprendizagem existia como prática social não regulamentada, cujo propósito moralizador e correcional era garantir o trabalho como remissão da ociosidade e delinquência infanto-juvenil. O segundo movimento, transcorrido até meados dos anos 1980, é marcado pelo 
ciclo desenvolvimentista e abundância de mão de obra. A Aprendizagem como política pública de qualificação para o mercado de trabalho nasce, nesse contexto, influenciada pela psicotécnica e patrocinada pelo patronato, que estimula a criação dos Serviços Nacionais de Aprendizagem (SNA) na condição de monopólio na formação de aprendizes.

Já o terceiro momento encontra-se em curso desde a redemocratização. Coincidente com uma conjuntura crítica articulada entre o esgotamento do projeto de industrialização nacional, crises políticas e desaceleração econômica, a política pública incorpora uma identidade moderna, desta vez, como programa de responsabilidade social das empresas (ASSUMPÇÃO RODRIGUES et al., 2008). Assim, entidades sociais tornam-se as grandes protagonistas da oferta de aprendizes ao lado dos SNA. O emprego do terceiro setor não se coaduna somente com a filosofia da reforma da administração pública (PEREIRA, 1995), mas com a lógica de modernização conservadora característica do Brasil. Sobre esse tema, Montaño (2002) afirma que a atuação das entidades sociais é marcada pelo "possibilismo", isto é, considera como fato consumado os modelos excludentes de escola e de atuação dos jovens no mundo do trabalho, temas sensíveis às questões de formação e empregabilidade.

Logo, no Brasil, a Aprendizagem não busca a reversão de status quo, e sim uma ação dentro da ordem, a qual reforça os estigmas dos públicos beneficiários dessas políticas públicas. Persiste, portanto, a ideia da Aprendizagem disponibilizada como elemento corretivo e moralizador, o autorreforço da trajetória de dependência brasileira - com característica marcadamente despolitizada. Assim, a noção de risco social ainda preenche a discussão das políticas públicas dirigidas à juventude (OLIVEIRA, 2011), neste caso, caracterizada pela desarticulação entre os mundos de educação e trabalho, de forma contraditória às demandas recorrentes por mão de obra qualificada por parte dos empregadores.

\section{- Índia}

Contando com uma força de trabalho que corresponde ao dobro da população do Brasil e Argentina somados, é natural compreender que a estrutura de educação profissional indiana não consiga acompanhar tamanhas dimensões, sobretudo quando se trata de um país com diversidades econômicas e sociais tão distintas. No entanto, observa-se o dilema de uma política pública que busca, de forma simultânea, oferecer alternativa aos maiores números mundiais de trabalho infantil e trabalho precário dos jovens, paralelamente a uma educação profissional que habilite sua população jovem ao cumprimento das expectativas de suporte a um desenvolvimento econômico de protagonismo global.
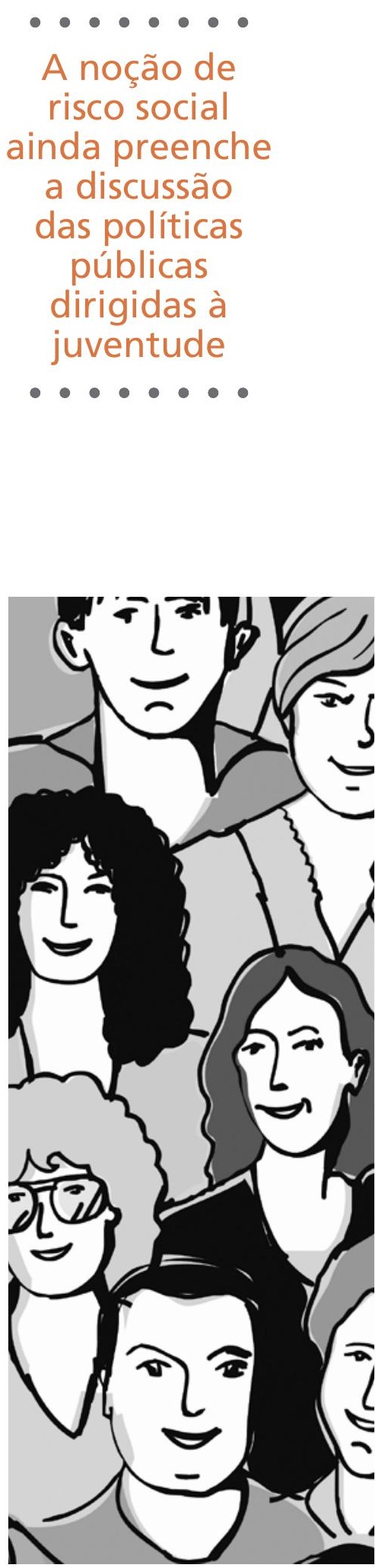

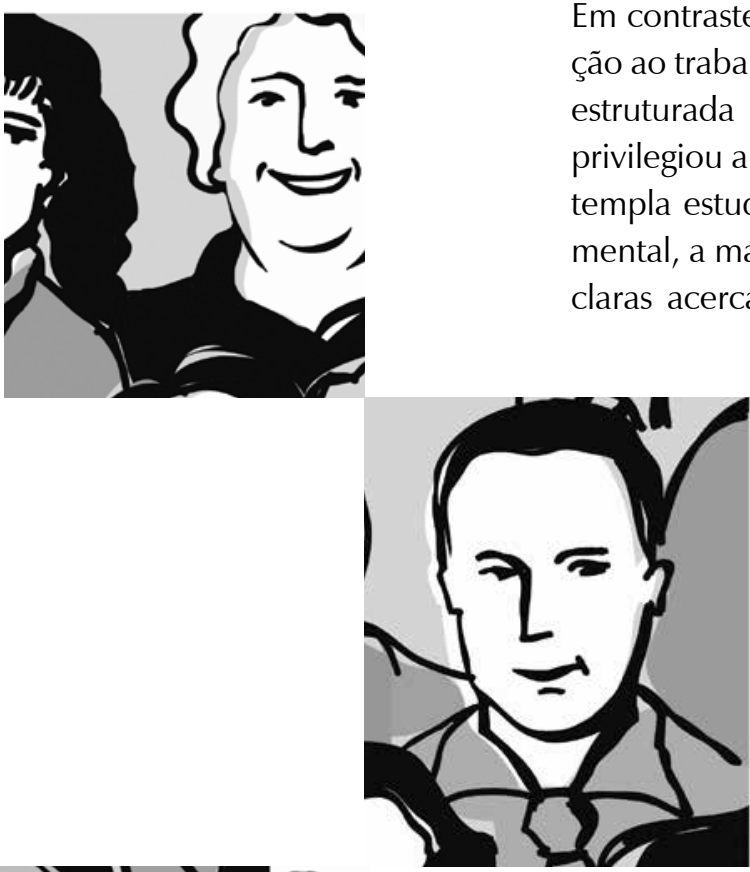

Em contraste com uma prática cultural sedimentada de longa data em relação ao trabalho de crianças e jovens, a Aprendizagem indiana foi legalmente estruturada em 1959 e implementada em 1962. Uma abordagem inicial privilegiou apenas aprendizes da área comercial, mas, a partir de 1973, contempla estudantes de áreas tecnológicas. Após alterações de caráter incremental, a mais recente inovação, datada de 1997, dispôs terminologias mais claras acerca da definição da prática profissional e responsabilidades das partes interessadas. Atualmente, a gestão da Aprendizagem indiana é compartilhada entre o Ministério do Trabalho e Emprego e o Ministério para Desenvolvimento dos Recursos Humanos, que segmentam a política pública indiana em quatro modalidades, de forma que somente aquela conhecida como "aprendizagem ocupacional" se dá sob a responsabilidade integral do Ministério do Trabalho.

De modo geral, a Aprendizagem não é bem-recebida pelos jovens, que rejeitam a longa duração dos programas, a predominância da orientação industrial e a baixa remuneração envolvida. Dessa forma, registraram-se apenas 215 mil aprendizes em 2013 (SMITH; KEMMIS, 2013). Trata-se de um problema crítico para um país onde a informalidade é realidade para 88,4\% dos jovens que compõem a força de trabalho indiana (OCDE, 2012). Além disso, problemas da estrutura da mão de obra indiana refletem no desenho de uma política pública de Aprendizagem que não gera os resultados esperados: excesso de graduados em cursos superiores para ocupações semiqualificadas; baixa oferta de mão de obra dirigida aos setores produtivos mais competitivos, a qual impede maior crescimento econômico nacional; problemas na formação de instrutores dirigidos à educação profissional; e finalmente, um descompasso entre os interesses das empresas (que assumem iniciativas próprias de qualificação de mão de obra) e o sistema de formação nacional segmentado conforme exposto, que impede maiores articulações e reconhecimento oficial (SMITH; KEMMIS, 2013).

Ao contrário dos modelos brasileiro e sul-africano, a Índia não passou por transformações da política pública, que implicariam em uma nova visão da Aprendizagem nacional. O que a torna crítica, no entanto, é menos sua incapacidade de dar respostas ao arranjo produtivo e uma perspectiva de trajetória profissional mais consolidada aos jovens. É, com efeito, a problemática de lidar, por gerações, com uma oferta de mão de obra muito superior à demanda. A educação profissional dirigida em termos de alinhamento à quantidade e qualidade demandada pelo setor produtivo torna-se uma tarefa muito complexa em termos de gestão da política pública. Dessa forma, a precarização quanto à inserção do jovem no mercado de trabalho, bem como o descompasso entre os universos da educação e do trabalho caracterizam a trajetória de dependência indiana. 


\section{- África do Sul}

De forma geral, as iniciativas para o desenvolvimento de um sistema nacional de políticas de educação profissional sul-africano, em caráter democrático, são relativamente recentes. Somente em 2009, uma estrutura executiva pública para pensar e gerir essas iniciativas foi constituída: o Departamento de Educação Superior e Treinamento. No entanto, é importante ressaltar que isso não significa compreender a Aprendizagem como política pública recente na África do Sul. Ao contrário, é antiga e tradicionalmente associada ao sistema de apartheid.

A segunda metade do século 20 apresentou um modelo de Aprendizagem sul-africana no qual "artisan training was the product of an interventionist state, and became synonymous with the privileges of white workers and the power of racially exclusive craft unions" (SMITH; KEMMIS, 2013, p.117). Dessa forma, sobretudo durante os anos 1960, os politicamente influentes sindicatos operários eram refratários a qualquer iniciativa de importação de mão de obra qualificada estrangeira não branca e promoção de mão de obra nacional não branca que influenciasse a estrutura elitizada dos operários qualificados sul-africanos. $\mathrm{O}$ fomento à contratação de aprendizes brancos era patrocinado por grandes empresas estatais, chegando à quantidade de 33 mil aprendizes em 1975. De fato, é possível concluir que a política pública foi empregada no apoio à sustentação do regime segregacionista.

O fim do apartheid, contudo, acarretou uma nova visão do sistema educacional do país, a qual ignorou qualquer atenção à educação profissional, uma vez que essa prática era culturalmente associada ao regime anterior e gozava de péssima reputação. A Aprendizagem sul-africana praticamente desapareceu após a privatização das grandes empresas estatais que davam sustentação à contratação dos aprendizes (sem, no entanto, ter sido abolida, já que os marcos legais permanecem desde 1981). A discussão sobre a retomada só se deu na virada do século 21 , em protocolos firmados, nacionalmente, a partir de 2006, para que a educação profissional do país negasse o legado anterior, que pouco contribuiu em termos de desenvolvimento econômico. Desde então, o desafio sul-africano é erguer uma ideia a partir de novos e significativos investimentos em infraestrutura dos centros profissionalizantes, recursos humanos habilitados e coordenação entre empresas e representantes sindicais.

Atualmente, o estágio de fortalecimento do sistema sul-africano revela carências em termos de averiguação dos currículos, para maior qualidade dos programas, além de participação mais enfática de empresas e sindicatos. A despeito da pequena quantidade de aprendizes, o governo pode perceber uma vitória em termos de mudança de perfil, uma vez que $73 \%$ dos jovens são não brancos (negros e asiáticos). No entanto, os desafios permanecem, afinal, a África do Sul é um dos países com índices altos de jovens entre 15 e

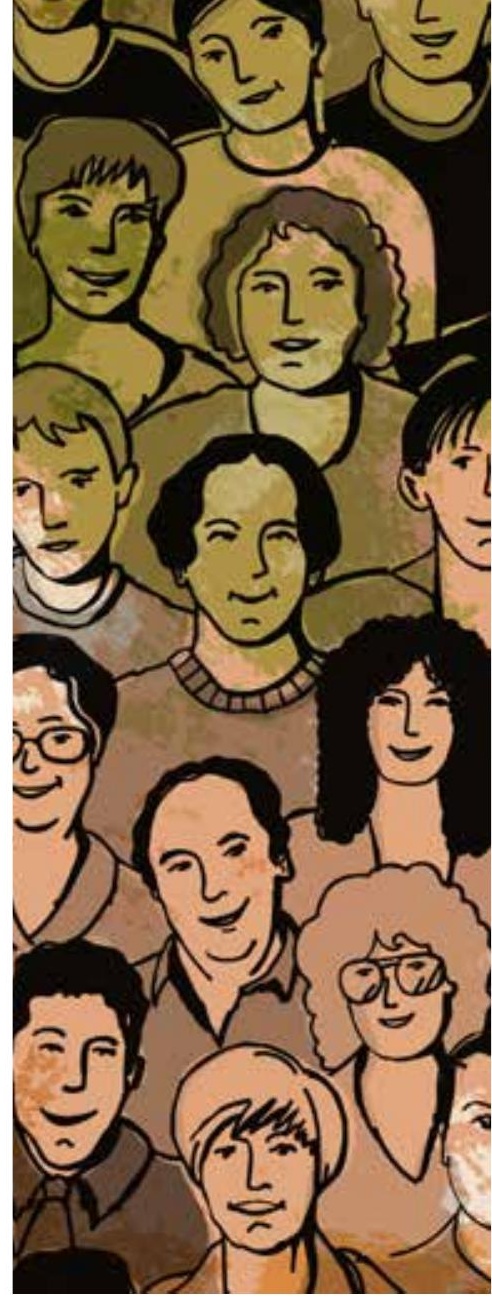

$\bullet \bullet \bullet \bullet \bullet$

A política pública foi empregada no apoio à sustentação do regime segregacionista

- $\bullet \bullet$ 


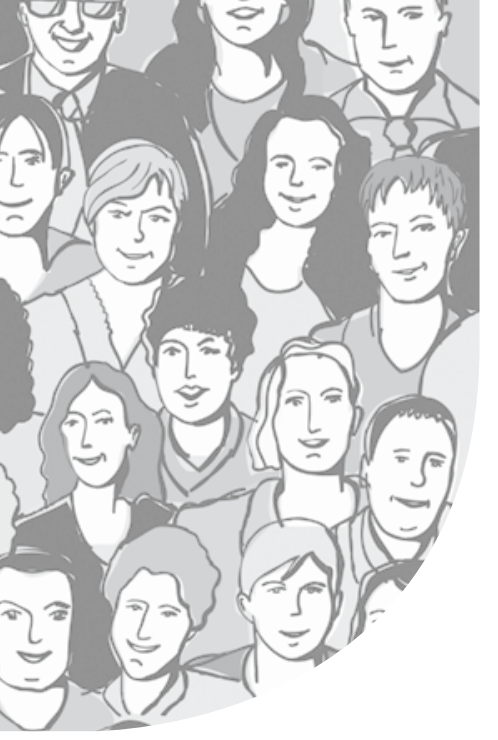

De fato, a Aprendizagem para os países europeus significa, em conjunto com outras políticas passivas e ativas de emprego e renda, um mecanismo de sustentação da malha social perante a estrutura dos Estados de bem-estar social desde a segunda metade do século 20. A educação profissional fora empregada como variante, mais ou menos articulada ao sistema educacional desses países, para que os jovens tivessem acesso ao mercado de trabaIho após o cumprimento da escolarização compulsória. A reestruturação da política pública nesses países, portanto, não significa o declínio dos Estados de bem-estar social, e sim um reflexo das iniciativas de reforma da administração pública para lidar de modo mais assertivo às expectativas de suas populações que ascenderam à agenda (KERSTENETZKY, 2012). Dessa forma, a Aprendizagem europeia tem buscado articular, de forma simultânea, uma política ativa de trabalho e emprego juvenil e a necessidade de fortalecimento da parametrização das qualificações do continente para garantir trânsito e o padrão de qualidade da mão de obra europeia. Portanto, a Aprendizagem foi e continua sendo um dispositivo a serviço do Estado de bem-estar social europeu, que se presta, fundamentalmente, à transição do jovem do mundo da educação para o mundo do trabalho, um atributo comum de suas trajetórias de dependência.

O modelo norte-americano, por sua vez, é um caso à parte, que implica em maior detalhamento. Alicerçado a uma malha de relações muito ampla e complexa em termos micro e macroeconômicos, a despeito das diferenças dos modelos europeus, a estrutura que depositou nas empresas a liberdade de formação de mão de obra implicou em resultados ao Estado de bem-estar social norte-americano e ao seu sistema produtivo. Assim, no que a Aprendizagem europeia fez diferença no tecido social e produtivo europeu, bem como na expectativa de qualificação de mão de obra de gerações, fez-se e continua fazendo-se desnecessária nos Estados Unidos. Portanto, o renascimento da Aprendizagem norte-americana não deixa de ser justificado para lidar muito mais com o desemprego juvenil do que propriamente buscar a qualificação de mão de obra. E, de uma forma simples, como de fato é o mecanismo da política pública e os estímulos proporcionados naquele país, registra-se, voluntariamente, uma quantidade maior do que é exigido de modo compulsório no Brasil e quase igual aos números da tradicional Aprendizagem francesa.

No caso da Aprendizagem dos países analisados dos Brics, há uma característica comum: uma problemática de imagem política. Nos termos de Baumgartner e Jones (2009), equilíbrios pontuados consolidam a manutenção dos monopólios políticos, isto é, arranjos institucionais restritos que reforçam uma compreensão consensual sobre determinados temas. Essas imagens, por vezes, atravessam o tempo (ainda que as arenas políticas se alterem) e são reflexos da trajetória de dependência solidificada por valores ano após ano. Eis porque, no Brasil, a Aprendizagem caracterizou-se e ainda se ca- 
racteriza no trato do jovem em "risco social", "marginalizado", "vulnerável" etc. Historicamente, ela não foi pensada e desenvolvida para integrar uma discussão mais ampla acerca da formação do tecido social e produtivo do país, tampouco, uma ação objetiva no combate ao desemprego juvenil. Ao contrário, manteve-se vigente e desarticulada às diversas iniciativas de programas educação profissional e reformas educacionais que foram e continuam sendo propostas, embora a premissa da cota se mantenha.

Na Índia, a complexidade de manter uma política pública com gestão executiva rivalizada entre dois órgãos do Estado é a menos crítica. A dificuldade maior é tornar a Aprendizagem uma trajetória efetiva de articulação do mundo da educação ao mundo do trabalho da sociedade indiana, cujo emprego da mão de obra juvenil de forma precária é visto com naturalidade. Na África do Sul, por sua vez, o desafio é desenvolver uma política pública que ressalte não apenas a indispensável perspectiva inclusiva e salutar articulação ao arranjo produtivo nacional, mas também uma resposta objetiva ao alarmante índice de desemprego juvenil. No caso da trajetória da política pública nesse país, não deixa de ser emblemático o contraste com a Alemanha, cuja Aprendizagem se fortaleceu bastante durante o regime nazista, mas na derrocada, não sucumbiu, foi acolhida pela sociedade alemã como tradição que supera os estigmas dos regimes antidemocráticos.

Em contraste, os números significativos de aprendizes formalizados na Europa refletem a maturidade de uma cultura de formação da iniciativa privada (em que pese sua heterogeneidade nacional e setorial) e a valorização histórica da educação pela sociedade civil e política (na condição de direito fundamental a todos). Reflete, também, a elevação do trabalho, em todos os sentidos, como parte integrante de um projeto de vida. A trajetória de dependência, nesse caso, mais do que estigmatizar a Aprendizagem, a fez sobreviver e até valorizar-se a despeito das conjunturas críticas.

Cumpre, por fim, repassar as disposições referentes aos países em desenvolvimento no contraste com os modelos europeus. Do ponto de vista histórico e funcional, a Aprendizagem dos Brics difere sistematicamente pela desvalorização da educação profissional, historicamente considerada como variante deslocada da realidade de ascensão educacional e profissional à qual a população almeja. O grande desafio dos países desenvolvidos europeus é valorizar a Aprendizagem para que ela não se configure social e economicamente da mesma forma (CENTRO EUROPEO PARA EL DESARROLLO DE LA FORMACIÓN PROFESIONAL, 2014). Ainda que nos Estados Unidos, por exemplo, a formação para o trabalho tenha sido um assunto mais pertinente à dinâmica da empresa do que do Estado, essa característica também foi deficitária no Brasil e na Índia, principalmente pela baixa competitividade existente e pela ampla disponibilidade de mão de obra.

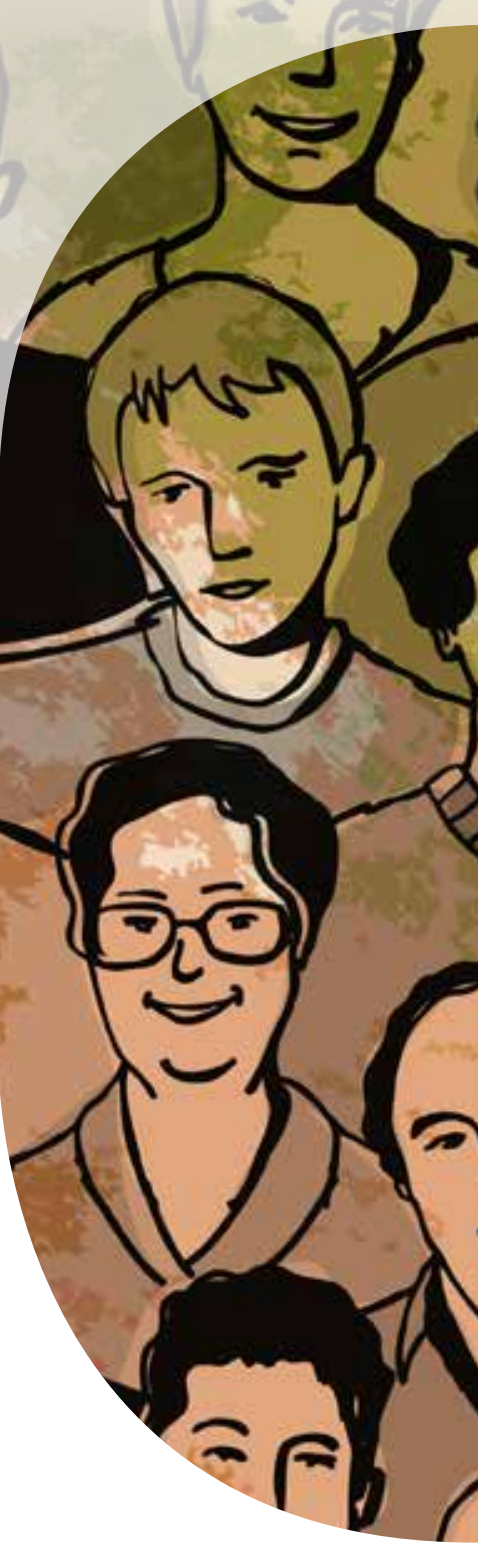




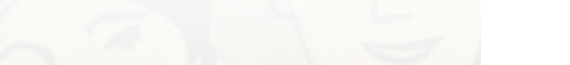

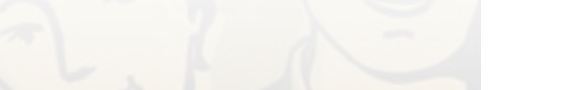
presas em qualificar pessoas e pela incapacidade das instituições formadoras em prover mão de obra qualificada e diversificada para atender às lacunas do mercado de trabalho formal de modo objetivo e integrado a uma agenda compartilhada com o setor produtivo.
\end{abstract}

Outros fatores, senão de suas trajetórias históricas, fatores constituintes da
relação capital-trabalho, que tem a emergência e o recuo de atores políticos
diversos para compor suas políticas de educação profissional, mais especi-
ficamente, a Aprendizagem. Assim, se a abordagem histórica é capital para
a análise, a investigação das políticas públicas tem o apoio do institucio-
nalismo histórico. Essa linha de estudo da Ciência Política permite que a
análise da trajetória de dependência das instituições, dos fenômenos a ela
relacionados como conjunturas críticas (PIERSON; SKOCPOL, 2008) e dos
equilíbrios pontuados (KRASNER, 1984) implique em arranjos e fins políticos
estáveis ou distintos ao longo do tempo (HOWLETT; RAMESH; PERL, 2013).

A análise referente à dinâmica relacional proeminente destaca um modelo bastante distinto nos casos dos países em desenvolvimento. Porque neles, Aprendizagem não se revela como mecanismo à disposição da sociedade para proporcionar meios de acesso aos atores envolvidos. Justifica-se a afirmação pela ausência de incentivos do Estado, pela baixa disposição das em-

Dessa forma, vê-se a grande variação sobre como a política de Aprendizagem está estruturada nos diversos países. Essa diversidade não resulta de outros fatores, senão de suas trajetórias históricas, fatores constituintes da relação capital-trabalho, que tem a emergência e o recuo de atores políticos diversos para compor suas políticas de educação profissional, mais especificamente, a Aprendizagem. Assim, se a abordagem histórica é capital para a análise, a investigação das políticas públicas tem o apoio do institucionalismo histórico. Essa linha de estudo da Ciência Política permite que a análise da trajetória de dependência das instituições, dos fenômenos a ela relacionados como conjunturas críticas (PIERSON; SKOCPOL, 2008) e dos estáveis ou distintos ao longo do tempo (HOWLETT; RAMESH; PERL, 2013).

\section{Notas}

${ }^{1}$ Aqui disposta com sua inicial maiúscula, para ressaltar a política pública de forma diferenciada à ação no campo conceitual da Pedagogia, no que se refere ao processo de assimilação da instrução e do ensino propriamente desenvolvido.

${ }^{2} \mathrm{O}$ sistema dual de educação profissional alemão contempla também outras possibilidades: 1 - Sistema dual no ensino superior, que se divide entre universidades e escolas superiores tecnológicas, sendo estas últimas orientadas na formação para o mercado de trabalho. Somente as universidades podem oferecer doutorados; e 2 - Sistema dual no ensino básico, que consiste na existência de três percursos educacionais possíveis e distintos entre si em relação ao tipo e à qualidade da educação oferecidos: Liceu (Gymnasium), Escolas Intermédias (Realschule) e sistema secundário baixo (Huptschule). A escolha de um dos três percursos se dá precocemente (por volta dos 10 anos de idade). Esse é o sistema mais reconhecido quando se fala em sistema dual de ensino alemão.

${ }^{3}$ A Aprendizagem francesa é um ramo do ensino secundário. Os jovens devem frequentar o nível secundário básico compulsório (college) e ascender 
ao nível secundário superior (lycée), com duração de três anos, geralmente, frequentado por jovens entre 15 e 18 anos, e permite três percursos: geral (baccalauréat general), propedêutico ao ensino superior acadêmico; tecnológico (baccalauréat technologique), com oitoáreastecnológicas para atuação profissional e acesso ao ensino superior de ramos tecnológicos; e profissionalizante (baccalauréat professionnel), com maior direcionamento ao mercado de trabalho. Além disso, os jovens podem optar pelos CFA (DIF, 2011).

${ }^{4} \mathrm{~A}$ Aprendizagem inglesa não demanda requisitos educacionais fixos. Há relativa flexibilidade no provimento da formação teórica (parcialmente financiada pelo Estado), que pode ser desenvolvida em centros privados, escolas de educação profissional públicas, universidades, grupos comunitários etc., que expedem a certificação. A Inglaterra não impõe restrições às empresas que queiram aderir ao programa e financia $100 \%$ da prática profissional.

${ }^{5}$ No fim do século 19, o perfil dos imigrantes era desprovido de qualificação profissional. Ora, se a mão de obra qualificada era rara e cara e a força de trabalho era abundante e barata, não foi coincidência que a produção em massa tenha se tornado realidade naquele país, no fim do século 19. Dessa forma,

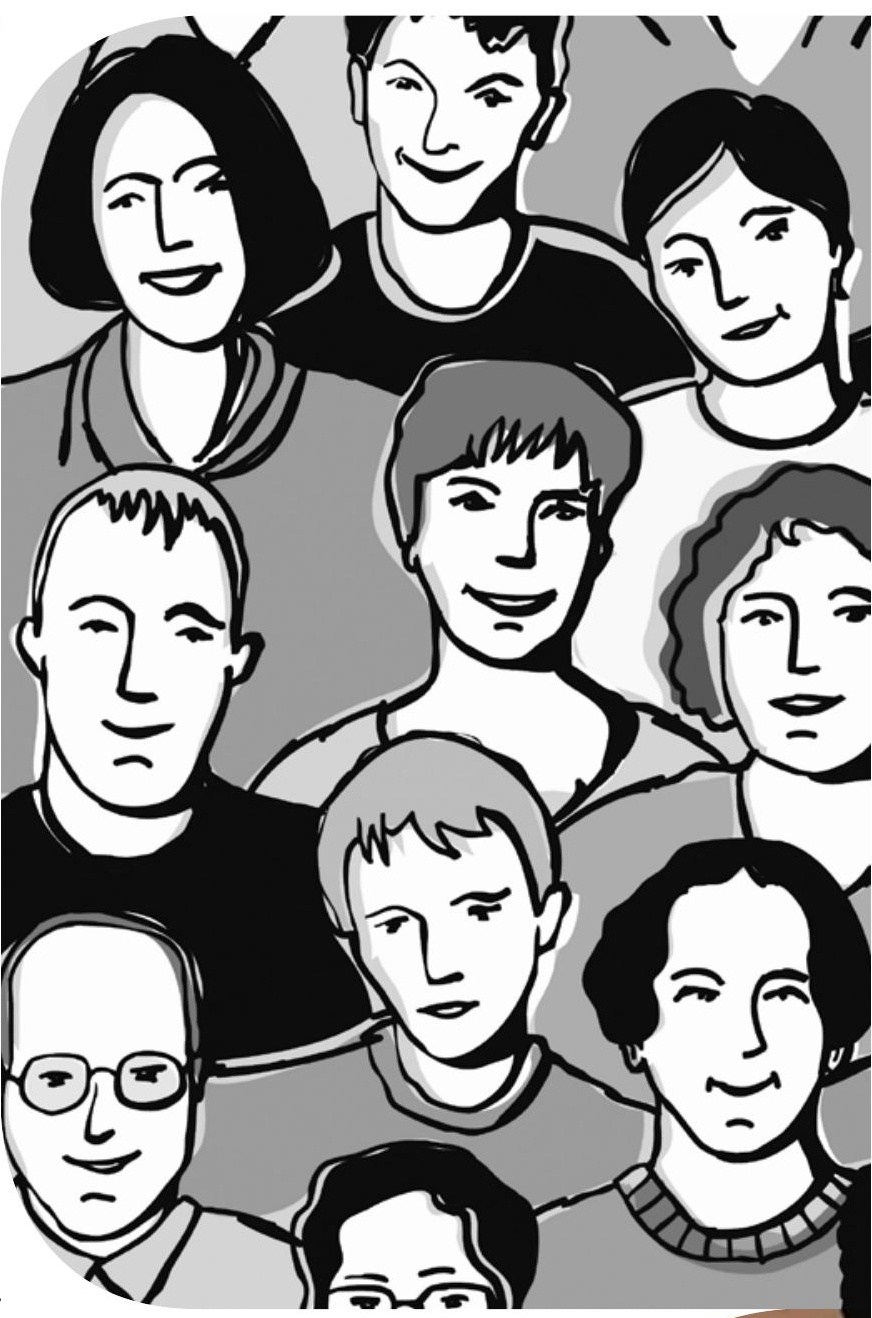
a Aprendizagem norte-americana é aquela que teve que conviver com o desenvolvimento industrial que a considerava, em sua essência como viabilizadora de mão de obra qualificada, um elemento a ser evitado. Não à toa, a racionalização da produção era a antítese de uma ideia tradicional da Aprendizagem europeia e sua negação se dava em dois sentidos: "American employers looked to craftsman not just to organize and manage production but also to serve as intermediaries in the labor market, recruiting skilled workers and presiding over the training of apprentices" (THELEN, 2004, p.186).

${ }^{6}$ A lei n.10.097/00, de 19 de dezembro de 2000, tornou compulsória uma cota de $5 \%$ a $15 \%$ adicional à quantidade de empregados, em grandes e médias empresas, que deve ser constituída por aprendizes formalizados. Além disso, de acordo com o Decreto n. 5.598, de 10 de dezembro de 2005, que regulamenta a contratação de aprendizes, ao efetivar o cálculo da cota, as empresas devem levar em consideração apenas as categorias funcionais consideradas como "qualificadas" pela Classificação Brasileira

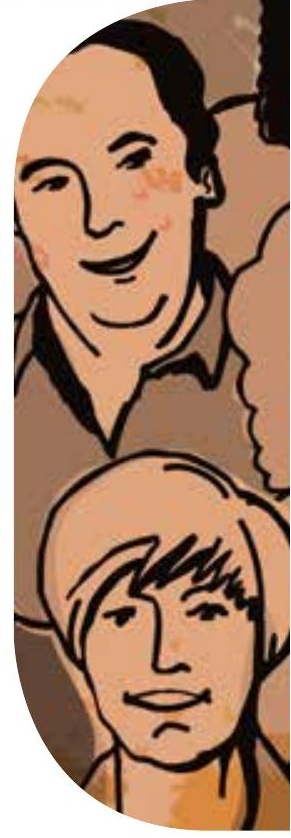




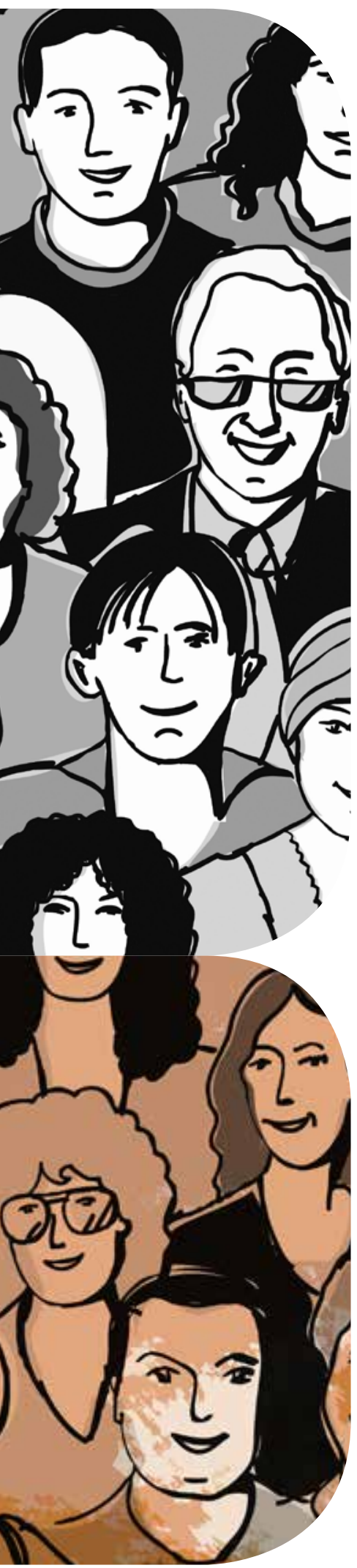

de Ocupações (CBO). Assim, ocupações que demandam formação técnica de nível médio e superior, além de cargos de chefia, aprendizes já contratados e funcionários contratados em regime temporário estão excluídos do cálculo da cota.

${ }^{7} \mathrm{~A}$ educação profissional brasileira que se presta à Aprendizagem é normatizada por uma oferta parametrizada pelo MTE, por meio de centenas de cursos com pelo menos 400 horas de formação teórica e 400 horas de atividades práticas nas empresas. Os contratos de trabalho devem durar exatamente o período da formação teórica e da atividade prática, simultâneos, por no máximo dois anos. Não há articulação efetiva entre a educação básica formal e os programas de Aprendizagem, no entanto, trata-se de um requisito: a relação trabalhista só é válida mediante frequência do aprendiz à escola básica, compulsória, se já não a tiver concluído. Foram registrados 327 mil contratos de aprendizagem em 2013.

${ }^{8}$ Sustentados por imposto de $1 \%$ da folha de pagamento das empresas, são entidades de direito privado direcionadas à qualificação de mão de obra para um setor econômico determinado. São geridas pela respectiva confederação patronal.

\section{Referências}

ADVISORY COMMITTEE ON APPRENTICESHIP. The future of the National Registered Apprenticeship System: a workforce strategy for Main Street America. [S.I.], Nov. 2008. Disponível em: <https://21stcenturyapprenticeship.workforce3one.org>. Acesso em: 2 jan. 2014.

ASSUMPÇÃO RODRIGUES, Marta Maria. Inequality, inclusion \& democracy in Brazil: origin \& evolution of education to employment policy. International Interdisciplinary Journal of Scientific Research, v. 1, n. 2, p. 1-12, Nov. 2014.

ASSUMPÇÃO RODRIGUES, Marta Maria. Skill formation, governance, and democracy in Brazil: the state of the art of a public policy. Notre Dame: Kellogg Institute for International Studies, Feb. 2013. (Working paper, 390).

ASSUMPÇÃO RODRIGUES, Marta Maria et al. Corporate social responsibility-CSR in two countries: Brazil and Norway. Oslo: Fafo, 2008.

BAUMGARTNER, Frank R.; JONES, Bryan. Agendas and instability in American politics. 2nd. ed. Chicago: University of Chicago Press, 2009.

BRASIL. Ministério do Trabalho e Emprego. Programa de Disseminação de Estatísticas do Trabalho (PDET): bases estatísticas RAIS/CAGED. Brasília, DF, 2014. Disponível em: <http://www2.mte.gov.br/pdet/ajuda/notas_comunic/Comu14709. asp>. Acesso em: 10 jun. 2014. 
CENTRO EUROPEO PARA EL DESARROLLO DE LA FORMACIÓN PROFESIONAL.

Desarrollo de la formación de aprendices. Nota Informativa, Salónica, mayo 2014. Disponível em: <www.cedefop.europa.eu/files/9088_es.pdf>. Acesso em: 10 jun. 2014.

DIF, M'Hamed. Comparative analysis of the development of apprenticeship in Germany, France, the Netherlands and the UK: apprenticeship in the France: institutional patterns, organization and methods. 2011. Disponível em: <http://www. adam-europe.eu/prj/7158/prd/3/1/2_Apprenticeship_France.pdf>. Acesso em: 20 jun. 2014.

DOLPHIN, Tony; LANNING, Tess. Rethinking apprenticeships. London: Institute for Public Policy Research, 2011. Disponível em: <http:// www.ippr.org/assets/media/images/media/ files/publication/2011/ 11/apprenticeships_ Nov2011_8028.pdf>. Acesso em: 19 abr. 2014.

FULLER, Alison; UNWIN, Lorna. Reconceptualising apprenticeship: exploring the relationship between work and learning. Journal of Vocational Education \& Training, v. 50, n. 2, p. 153-173, 1998. Disponível em: <http://dx.doi. org/10.1080/13636829800200043>. Acesso em: 19 abr. 2014.

THE FUTURE of apprenticeships in England: next steps from Richard review. London: Department of Education: Department for Business Innovation \& Skills, 2013. Disponível em: <https://www.gov.uk/ government/uploads/system/uploads/attachment_ data/file/190632/bis-13-577-the-future-of-apprenticeships-in-england-next-steps-from-the-richard-review.pdf>. Acesso em: 19 maio 2013.

HOWLETT, Michael; RAMESH, M; PERL, Anthony. Política pública: seus ciclos e subsistemas. 3. ed. Rio de Janeiro: Elsevier, 2013.

KERSTENETZKY, Célia Lessa. 0 estado do bem-estar social na idade da razão: a reinvenção do estado social no mundo contemporâneo. Rio de Janeiro: Elsevier, 2012.

KING, Desmond. The conservatives and training policy, 1979-1992: from a tripartite to a neo-liberal regime. Political Studies, v. 41, n. 2, p. 214-235, 1993.

KRASNER, Stephen. Approaches to the state: alternative conceptions and historical dynamics. Comparative Politics, v. 16, n. 2, p. 223-246, 1984. Disponível em: <http://www.jstor.org/stable/421608>. Acesso em: 3 nov. 2013.

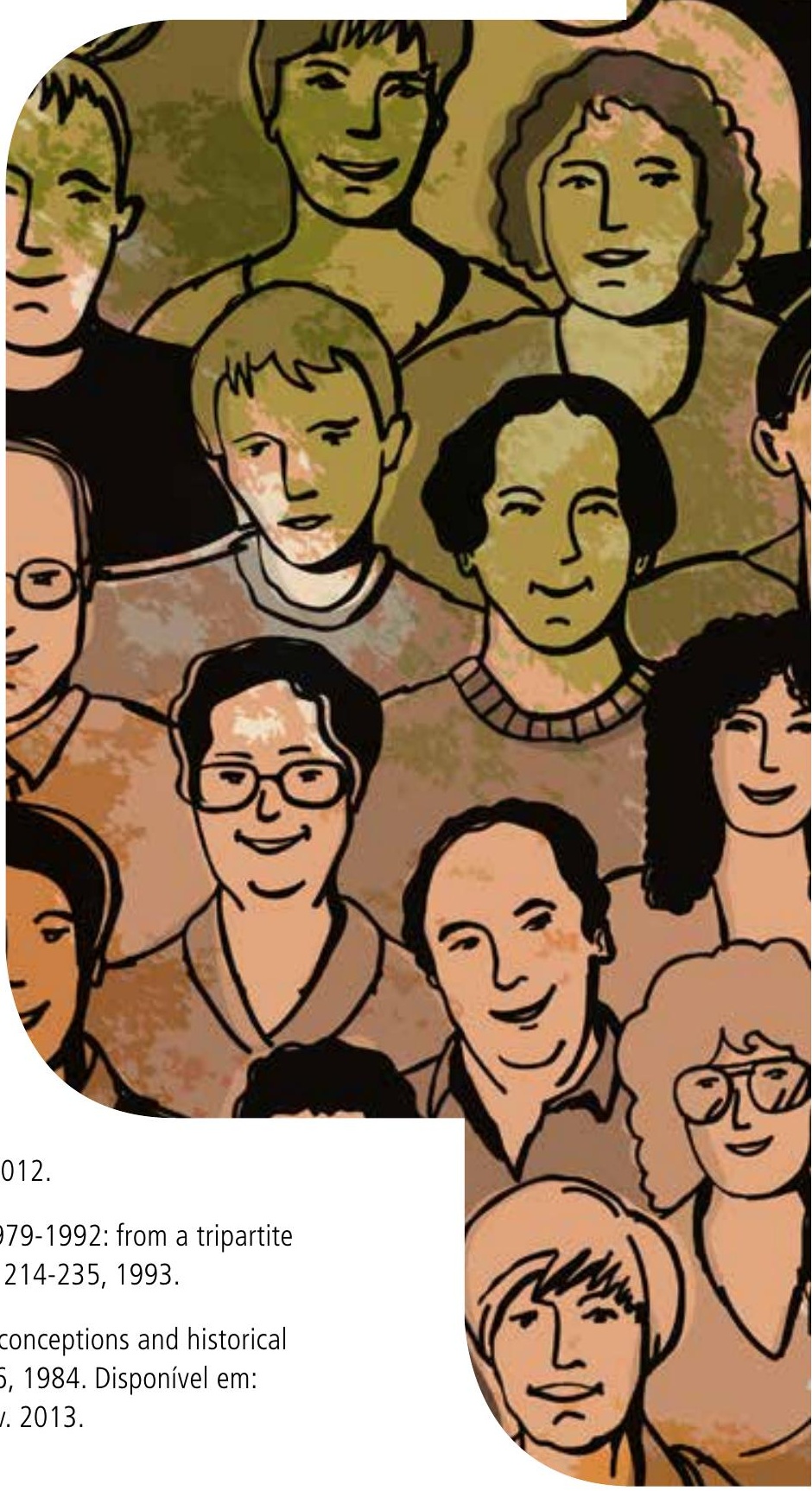


RAIKES, Luke. Learner drivers: local authorities and apprenticeships. London: Institute for Public Policy Research, June 2015.

SCHRIEWER, Jürgen. Comparación y explicación en el análisis de los sistemas educativos. Revista de Educación. Los usos de la comparación en Ciencias Sociales y en Educación, Madrid, 1990. Número extraordinario. Disponivel em: <http://redined. mecd.gob.es/xmlui/bitstream/handle/11162/81710/00820073006180.pdf>. Acesso em: 29 jun. 2014.

SMITH, Erica; KEMMIS, Ros Brennan. Towards a model apprenticeship framework: a comparative analysis of national apprenticeship systems. Geneve: International Labour Office: World Bank, 2013. Disponível em: <http://www.ilo. org/wcmsp5/groups/public/---asia/---ro-bangkok/---sro new_delhi/documents/ publication/wcms_234728.pdf>. Acesso em: 7 mar. 2014.

STEEDMAN, Hillary. The state of apprenticeship in 2010: international comparisons. London: London School of Economics and Political Science: Centre for Economic Performance, 2010. Disponível em: <http://cep.lse.ac.uk/pubs/downloads/special/ cepsp22.pdf>. Acesso em: 30 jul. 2014.

THELEN, Kathleen. How institutions evolve: insights from comparative historical analysis. In: MAHONEY, James; RUESCHEMEYER, Dietrich (Org.). Comparative historical analysis in the social sciences. Cambridge: Cambridge University Press, 2003.

THELEN, Kathleen. How institutions evolve: the political economy of skills in Germany, Britain, the United States and Japan. Cambridge: Cambridge University Press, 2004.

UNITED STATES. Department of Labor. $\mathbf{2 1}^{\text {th }}$ Century registered apprenticeship: educate, build, innovate. Washington, DC, 2013. Disponível em: <https://21stcenturyapprenticeship.workforce3one.org>. Acesso em: 2 jan. 2014.

VELOSO, José Rodrigo Paprotzki. Aprendizagem: metamorfose de uma política pública de educação e trabalho dirigida à juventude. 2015. Dissertação (Mestrado em Gestão de Políticas Públicas) - Escola de Artes, Ciências e Humanidades, Universidade de São Paulo, São Paulo, 2015. 


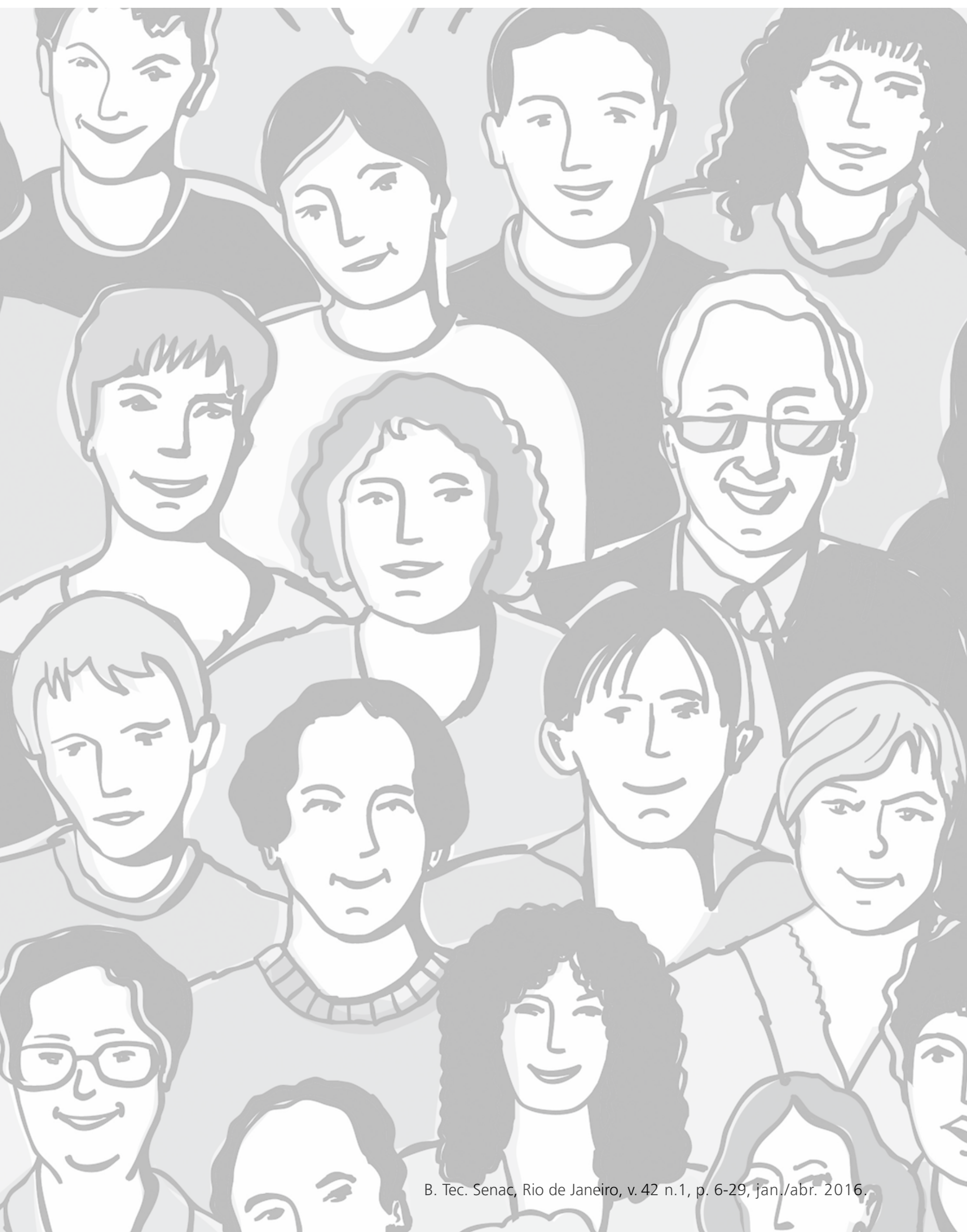

